\title{
PERANCANGAN APLIKASI GAJI KARYAWAN PADA PT. PP LONDON SUMATRA INDONESIA Tbk. GUNUNG MALAYU ESTATE - KABUPATEN ASAHAN
}

\author{
Adi Widarma*1, Sri Rahayu ${ }^{2}$ \\ Program Studi Teknik Informatika, Universitas Asahan \\ Jl. Jend. Ahmad Yani Kisaran 21244, Sumatera Utara \\ Email : adiwidarma@una.ac.id ${ }^{* 1}$, ayurahayu.as5@gmail.com²
}

\begin{abstract}
Abstrak - Gaji merupakan upah yang diberikan kepada karyawan yang telah bekerja pada sebuah perusahaan atau instansi tertentu. Setiap karyawan yang bekerja di sebuah perusahaan berhak mendapatkan gaji sesuai peraturan atau ketentuan yang ada di perusahaan tersebut. Masalah pemberian gaji merupakan hal yang penting karena mempunyai pengaruh yang sangat besar terhadap semangat kerja para karyawannya. Pada PT. PP London Sumatra Indonesia Tbk, Gunung Malayu Estate, aplikasi yang digunakan untuk pengolahan data penggajian karyawannya adalah aplikasi Microsoft Office Excel 2010. Maka dilakukan analisis suatu sistem pengolahan data gaji karyawan pada PT. PP. London Sumatra Indonesia Tbk dengan merancang aplikasi pemrograman menggunakan NetBeans IDE 7.2.1 dengan database MySQI. Sehingga dengan adanya aplikasi pengolahan data penggajian karyawan ini, maka akan meningkatkan kualitas pelayanan terhadap karyawannya, karena akan menghemat waktu dalam pemprosesan data, serta menghemat waktu dalam laporan penggajian.
\end{abstract}

Kata Kunci : aplikasi, sistem gaji, netbeans, mysql

Abstract - Salary is a salary given to employees who have worked for a particular company or agency. Every employee who works at the company is entitled to get approval according to the provisions of the company. The issue of providing assistance is important because it has a great importance to the morale of its employees. At PT. PP London Sumatra Indonesia Tbk, Gunung Malayu Estate, the application used to process employee payroll data is the Microsoft Office Excel 2010 application. An analysis was made for the employee payment data processing system at PT. PP London Sumatra Indonesia Tbk by supporting programming applications using NetBeans IDE 7.2.1 with MySQI database. Because by using this employee payroll data processing application, it will improve the quality of service to its employees, because it will save time in data processing, as well as save time in payroll reports.

Keywords : application, receiver system, netbeans, mysql

\section{PENDAHULUAN}

Gaji merupakan upah yang diberikan kepada karyawan yang telah bekerja pada sebuah perusahaan atau instansi tertentu. Setiap karyawan yang bekerja di sebuah perusahaan berhak mendapatkan gaji sesuai peraturan atau ketentuan yang ada di perusahaan tersebut. Seperti halnya pada PT. PP London Sumatra Indonesia Tbk, Gunung Malayu Estate perusahaan ini bergerak di bidang perkebunan.

Masalah pemberian gaji merupakan hal yang penting karena mempunyai pengaruh yang sangat besar terhadap semangat kerja para karyawannya. Pada PT. PP London Sumatra Indonesia Tbk, Gunung Malayu Estate, aplikasi yang digunakan untuk pengolahan data penggajian karyawannya adalah aplikasi Microsoft Office Excel 2010. Pada awalnya karyawan mengumpulkan surat pendukung absensi yang berisi lembar 
absensi dan surat izin apabila tidak bekerja serta surat keterangan lembur ke bagian administrasi keuangan, setelah itu administrasi keuangan akan menghitung gaji bruto terlebih dahulu untuk digunakan oleh bagian akuntansi dalam menghitung potongan pajak dengan mengentrikan no badge karyawan dan bagian departemennya, gaji pokok dan tunjangan. Setelah mendapatkan potongan pajak dari bagian akuntansi, bagian keuangan akan menghitung gaji bersih setiap karyawan dengan mengentrikan no badge, bagian, data lembur, uang makan, uang transport, dan potongan absensi kehadiran secara satu-persatu ke dalam aplikasi Microsoft Office Excel 2010.

Berdasarkan uraian yang telah dijelaskan diatas, diambil judul "Analisis Sistem Aplikasi Data Gaji Karyawan pada PT. PP London Sumatra Indonesia Tbk, Gunung Malayu Estate" melalui aplikasi pemrograman NetBeans IDE 7.2.1 dengan menggunakan database $\mathrm{MySQl}$ yang dapat membuat dan menyimpan ribuan tabel data.

\section{LANDASAN TEORI}

\subsection{Pengertian Sistem}

Menurut Jesa Ariawan dan Sri Wahyuni (2015), sistem adalah kumpulan dari sub-sub sistem baik sistem abstrak maupun fisik yang saling terintegrasi dan berkolaborasi untuk mencapai tujuan tertentu. Sistem adalah setiap sesuatu yang terdiri dari obyek-obyek, atau unsur-unsur, atau komponen - komponen yang bertata kaitan dan bertata hubungan satu sama lain, sedemikian rupa sehingga unsur-unsur tersebut merupakan satu kesatuan pemrosesan atau pengolahan yang tertentu.

Suatu sistem pada dasarnya adalah sekelompok unsur yang erat hubungannya satu dengan yang lain yang berfungsi bersama-sama untuk mencapai tujuan tertentu. Definisi ini dapat dirinci lebih lanjut tentang pengertian sistem secara umum, yaitu:

a. Setiap sistem terdiri dari unsur-unsur, seperti sistem pernafasan kita terdiri dari suatu kelompok unsur, yang terdiri dari hidung, saluran pernafasan, paru-paru, dan darah.

b. Unsur-unsur tersebut merupakan bagian terpadu sistem yang bersangkutan, unsur-unsur sistem berhubungan erat satu dengan yang lain dan sifat serta kerjasama antara unsur sistem tersebut mempunyai bentuk tertentu.

c. Unsur sistem tersebut bekerjasama untuk mencapai tujuan sistem, setiap sistem mempunyai tujuan tertentu. Seperti sistem pernafasan kita bertujuan menyediakan oksigen dan pembuangan karbon dioksida dari tubuh kita bertujuan menyediakan oksigen dan tersebut yang berupa hidung, saluran pernafasan, paruparu, dan darah bekerjasama satu dengan yang lain dengan proses tertentu untuk mencapai tujuan tersebut.

Suatu sistem merupakan bagian dari sistem lain yang lebih besar, sistem pernafasan kita merupakan bagian dari sistem metabolisme tubuh, contoh sistem lain adalah sistem pencernaan makanan, sistem peredaran darah, dan sistem pertahanan tubuh.

\subsection{Pengertian Aplikasi}

Menurut Hasan Abdurahman dan Asep Ririh Riswaya (2014), aplikasi adalah program siap pakai yang dapat digunakan untuk menjalankan perintah-perintah dari pengguna aplikasi tersebut dengan tujuan mendapatkan hasil yang lebih akurat sesuai dengan tujuan pembuatan aplikasi tersebut, aplikasi mempunyai arti yaitu pemecahan masalah yang menggunakan salah satu teknik pemrosesan data aplikasi yang biasanya berpacu pada sebuah komputansi yang diinginkan atau diharapkan maupun pemrosesan data yang diharapkan. Pengertian aplikasi secara umum adalah alat terapan yang difungsikan secara khusus dan terpadu sesuai kemampuan yang dimilikinya, aplikasi merupakan suatu perangkat komputer yang siap pakai bagi user.

Pengertian aplikasi menurut para ahli :

$$
\begin{array}{llr}
\text { a. Pengertian } & \text { aplikasi } & \text { menurut } \\
\text { Jogiyanto } & (1999: 12) & \text { adalah }
\end{array}
$$
penggunaan dalam suatu komputer, instruksi (instruction) atau pernyataan (statement) yang disusun sedemikian sehingga komputer dapat memproses input menjadi output. 
b. Pengertian aplikasi menurut Kamus Besar Bahasa Indonesia adalah penerapan dari rancang system untuk mengolah data yang menggunakan aturan atau ketentuan bahasa pemrograman tertentu. Aplikasi adalah suatu program komputer yang dibuat untuk mengerjakan dan melaksanakan tugas khusus dari pengguna.

c. Menurut Wikipedia, aplikasi adalah suatu subkelas perangkat lunak komputer yang memanfaatkan kemampuan komputer langsung untuk melakukan suatu tugas yang diinginkan pengguna.

\subsection{Definisi Database}

Menurut Cosmas Eko Suharyanto, Dkk. (2017) database adalah kumpulan data terstruktur. Agar dapat menambahkan, mengakses, dan memproses data yang tersimpan dalam database komputer, dibutuhkan sistem manajemen basis data (database management system).

Dalam pengembangan perangkat lunak tradisional yang memanfaatkan pemrosesan file, setiap kelompok pengguna menyimpan file-file-nya sendiri untuk menangani aplikasi pengolahan datanya masing-masing. Hal ini mengakibatkan adanya kerangkapan data atau disebut dengan redundancy.

Redundansi dalam proses penyimpanan data yang terjadi berkali kali dapat mengakibatkan beberapa masalah. Pertama, ada kebutuhan untuk melakukan pembaruan logis tunggal, misalnya seperti memasukkan data pada siswa baru beberapa kali: satu kali untuk setiap file tempat data siswa direkam. Hal ini menyebabkan duplikasi data. Kedua, ruang penyimpanan terbuang ketika data yang sama disimpan berulang kali, dan masalah ini mungkin serius untuk database yang besar. Ketiga, file yang mewakili data yang sama mungkin menjadi tidak konsisten. Hal ini bisa terjadi karena update diaplikasikan pada beberapa file tapi tidak untuk file yang lain.

\section{$2.4 \quad$ Flow Of Document (FOD)} Menurut Meza Silvana, Dkk. (2015)
FlowMap atau juga dapat disebut block chart atau Flow Of Document (FOD) /bagan alir merupakan penggambaran secara grafik dari langkah-langkah dan urutan-urutan prosedur dari suatu program. Flowmap efektif digunakan untuk menggambarkan proses maupun prosedur dalam sebuah organisasi. Flowmap digunakan untuk menggambarkan urutan prosedur/proses kerja dalam pembuatan sistem.

Ada beberapa hal yang harus diperhatikan oleh seorang analis dan programmer akan membuat flowmap, diantaranya beberapa petunjuk yang harus diperhatikan secara detail, seperti :

a. Flowmap digambarkan dari halaman atas ke bawah dan dari kiri ke kanan.

b. Durasi waktu aktivitas dimulai dan berakhir harus ditentukan secara jelas.

c. Setiap langkah dari aktivitas harus diuraikan dengan menggunakan deskripsi kata kerja yang jelas.

\subsection{Pengertian UML (Unified Modelling Language) \\ Menurut Windu Gata, Grace} (2013:4), Unified Modeling Language (UML) adalah bahasa spesifikasi standar yang dipergunakan untuk mendokumentasikan, menspesifikasikan dan membanngun perangkat lunak. UML merupakan metodologi dalam mengembangkan system berorientasi objek dan juga merupakan alat untuk mendukung pengembangan sistem.

Menurut Ade Hendini (2016), alat bantu yang digunakan dalam perancangan berorientasi objek berbasiskan UML adalah sebagai berikut:

\subsubsection{Use Case Diagram}

Use case diagram merupakan pemodelan untuk kelakuakn (behavior) sistem informasi yang akan dibuat. Use case digunakan untuk mengetahui fungsi apa saja yang ada di dalam sistem informasi dan siapa saja yang berhak menggunakan fungsi-fungsi tersebut.

2.5.2 Diagram Urutan (Sequence Diagram)

Sequence Diagram menjelaskan interaksi objek yang disusun berdasarkan urutan waktu. Secara mudahnya sequence diagram adalah gambaran tahap demi tahap, termasuk kronologi (urutan) perubahan secara logis yang seharusnya dilakukan untuk 
menghasilkan sesuatu sesuai dengan use case diagram.

2.5.3 Diagram Aktivitas (Activity Diagram)

Activity Diagram menggambarkan berbagai alir aktivitas dalam sistem yang sedang dirancang, bagaimana masing-masing alir berawal, decision yang mungkin terjadi, dan bagaimana mereka berakhir. Activity diagram juga dapat menggambarkan proses paralel yang mungkin terjadi pada beberapa eksekusi.

\subsubsection{Diagram Kelas (Class Diagram)}

Merupakan hubungan antar kelas dan penjelasan detail tiap-tiap kelas di dalam model desain dari suatu sistem, juga memperlihatkan aturan-aturan dan tanggung jawab entitas yang menentukan perilaku sistem. Class Diagram juga menunjukkan atribut-atribut dan operasi-operasi dari sebuah kelas dan constraint yang berhubungan dengan objek yang dikoneksikan.

\section{ANALISA DAN PERANCANGAN}

\subsection{Analisis Sistem Yang Berjalan}

\subsubsection{Analisis Dokumen}

Analisis Dokumen ini dilakukan untuk mengetahui dokumen apa saja yang menjadi input, proses, dan output dari sistem ini. Dokumen input adalah dokumen yang akan diproses oleh sistem yang biasanya dilakukan oleh entitas luar sistem. Dokumen proses adalah dokumen yang diperlukan oleh sistem dalam melakukan kegiatan pemrosesan data, sedangkan yang menjadi dokumen output adalah dokumen yang dihasilkan oleh proses olahan sistem, yang berasal dari dalam sistem ke entitas luar.

Adapun dokumen-dokumen yang digunakan dalam mengolah data perhitungan gaji karyawannya adalah :

1. Nama Dokumen : Data karyawan

Fungsi : Berisi keterangan data karyawan

Sumber : Bagian Administrasi Keuangan Aliran Data : dari bagian Administrasi Keuangan ke bagian Akuntansi

2. Nama Dokumen : Data penggajian dan tunjangan

Fungsi : Untuk mengetahui hasil dari proses perhitungan gaji
Sumber : Bagian Akuntansi

Aliran Data : dari bagian Akuntansi ke Direksi

3. Nama Dokumen : Laporan Data karyawan

Fungsi : Berisi laporan keterangan data karyawan

Sumber : Bagian Administrasi Keuangan Aliran Data : dari bagian Administrasi Keuangan ke bagian Akuntansi

4. Nama Dokumen : Laporan Data Gaji karyawan

Fungsi : Berisi laporan data gaji karyawan

Sumber : Bagian Akuntansi

Aliran Data : dari bagian Akuntansi ke bagian Administrasi Keuangan dan Direksi.

\subsubsection{Flow Map Yang Sedang Berjalan}

Flow Map merupakan gambaran secara keseluruhan sistem, berikut dibawah ini adalah gambaran flow map yang sedang berjalan :

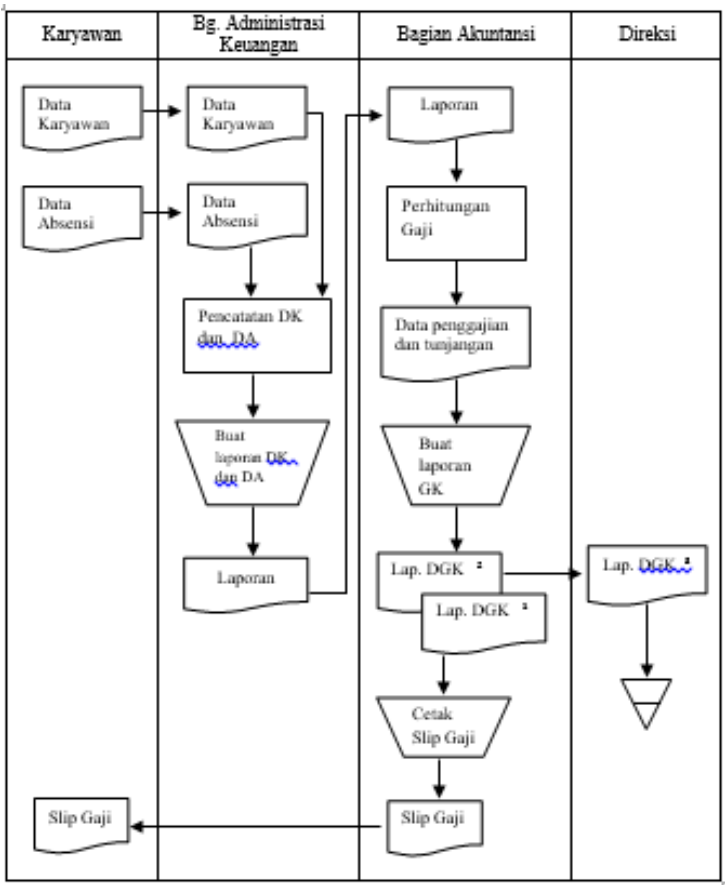

Gambar 1. Flow Map Yang Sedang Berjalan

Keterangan :

DK : data karyawan

DA : data absensi

DGK : arsip data gaji karyawan 


\subsection{Perancangan Sistem Yang Diusulkan}

Perancangan Sistem bertujuan untuk memberikan gambaran umum pengembangan sistem usulan yang dapat memberikan spesifikasi sistem usulan perangkat lunak kepada pengguna dengan menganalisis kelemahan dalam mengembangkan sistem yang telah ada demi kepuasan, kenyamanan dan kemudahan. Mempunyai database tersendiri untuk penyimpanan data gaji karyawan dan dalam penyajian laporan lebih mudah dan tidak mengalami banyak kesalahan dalam pendataan.

\subsubsection{Flow Map Yang Diusulkan}

Flow Map merupakan gambaran secara keseluruhan sistem, berikut dibawah ini adalah gambaran flow map yang diusulkan.

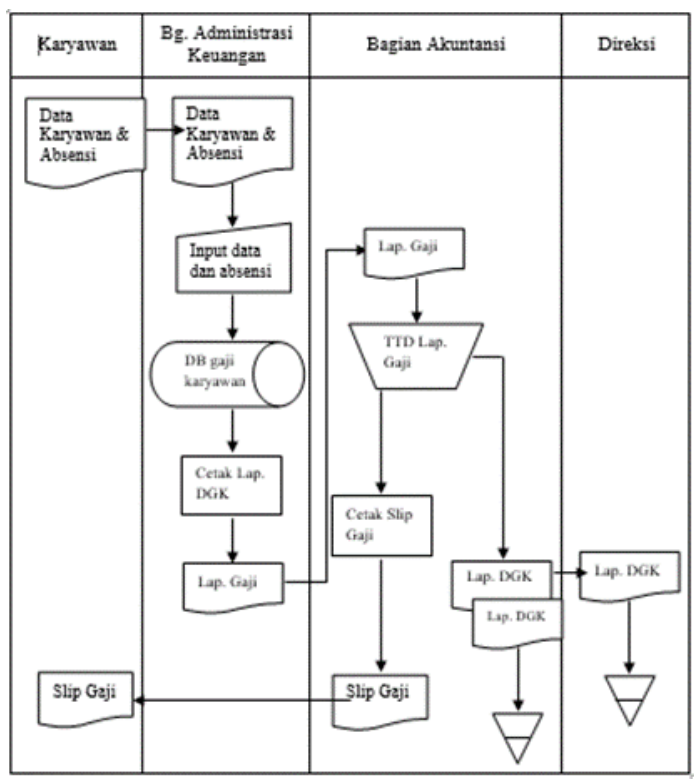

Gambar 2. Flow Map Yang Diusulkan

\subsection{Analisis Dengan Perancangan Terstruktur}

\subsubsection{Use Case Diagram}

$$
\text { Berikut ini merupakan }
$$

penggambaran use case diagram penggajian karyawan:

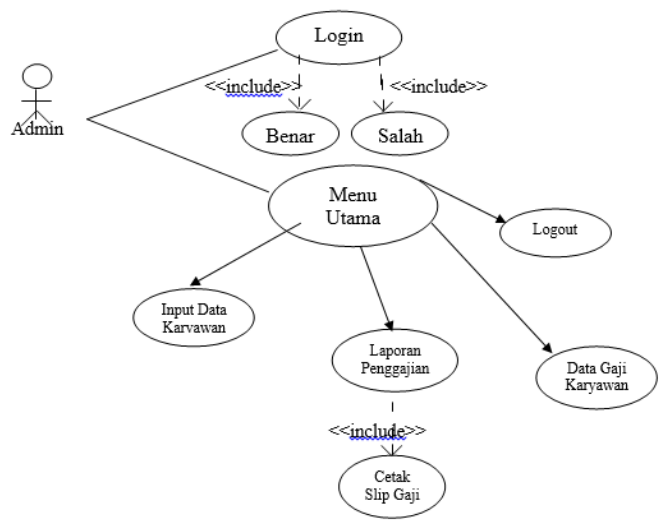

Gambar 3. Use Case Diagram

\subsubsection{Sequence Diagram}

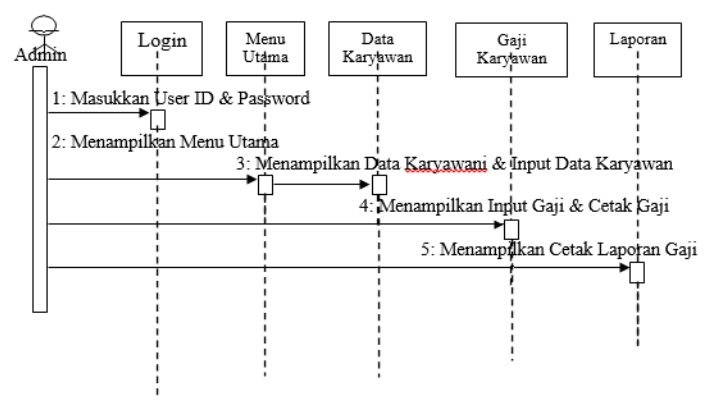

Gambar 4. Sequence Diagram

\subsubsection{Class Diagram}

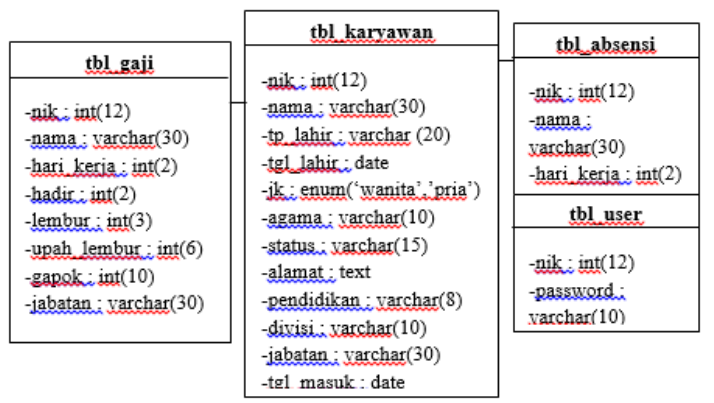

Gambar 5. Class Diagram 


\subsubsection{Activity Diagram}

Berikut ini adalah Activiy diagram penggajian karyawan :

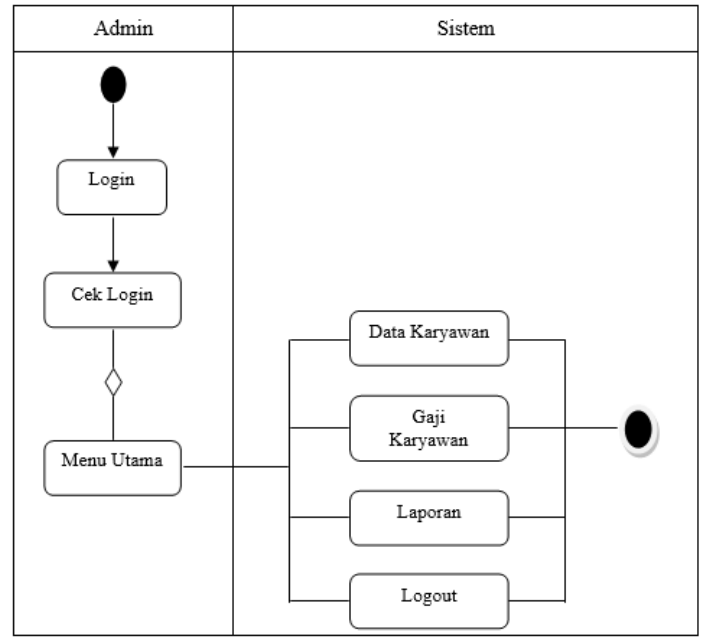

Gambar 6. Activity Diagram

\section{HASIL DAN PEMBAHASAN}

Mengimplementasikan sistem merupakan tahap pengujian dimana desain sistem dapat berjalan dengan baik. Implementasi harus sesuai dengan hasil analisis sistem. Pada tahap ini merupakan langkah-langkah dari pemakian program Analisis Sistem Aplikasi Data Gaji Karyawan pada PT. PP London Sumatra Indonnesia Tbk, Gunung Malayu Estate. Berikut penjelasan program:

\section{a. Form Login}

Form ini digunakan untuk login ke aplikasi. Berdasarkan gambar tampilkan rancangan login, maka dijelaskan bahwa pada sistem harus melakukan login dengan memasukkan username dan password secara benar agar dapat masuk ke dalam sistem aplikasi.

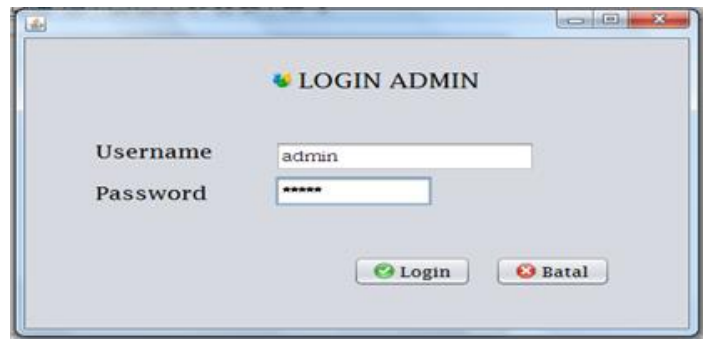

Gambar 7. Rancangan Layar Login Admin b. Form Menu Utama

Berdasarkan gambar rancangan menu utama pada gambar 8, maka dapat dijelaskan bahwa halaman ini akan ditampilkan oleh sistem setelah berhasil melakukan login. Pada halaman ini pengguna dapat memilih menu-menu pada sistem untuk masuk ke modul-modul sistem yang diinginkan.

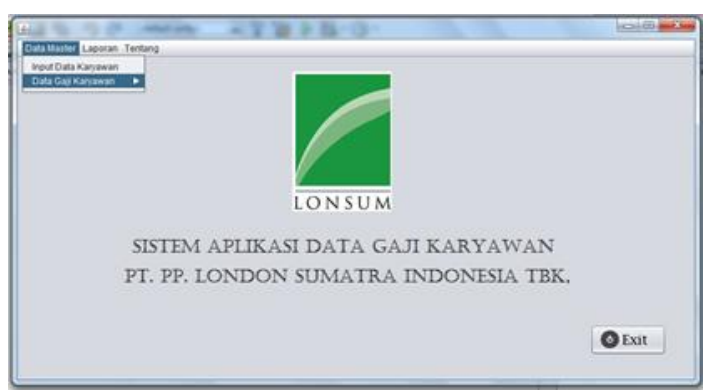

Gambar 8. Rancangan Layar Menu Utama

\section{c. Form Input Data Karyawan}

Berdasarkan rancangan input master karyawan seperti yang ditunjukkan pada gambar 9, maka dapat dijelaskan pada rancangan ini ditampilkan kotak-kotak teks untuk inputan data karyawan. Pada rancangan ini admin dapat melakukan penambahan data-data karyawan.

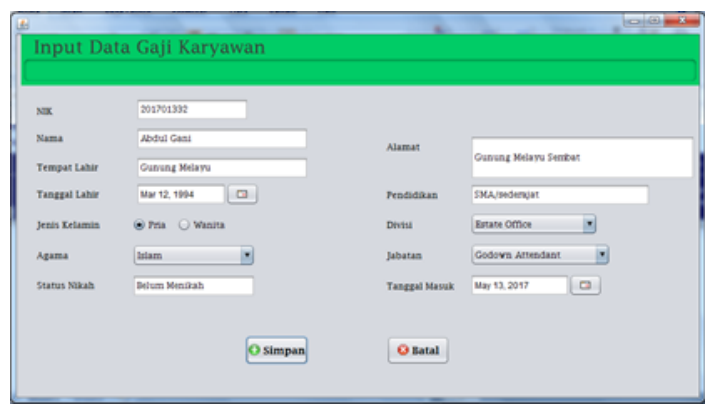

Gambar 9. Rancangan Layar Input Data Karyawan

d. Form Daftar Data Gaji Karyawan

Berdasarkan rancangan ouput laporan karyawan seperti yang ditunjukkan pada gambar 10, maka dapat dijelaskan pada halaman ini ditampilkan tabel yang berisi data-data karyawan yang sudah diinput sebelumnya. Pada halaman ini admin dapat melakukan pengelolaan data karyawan yaitu mengubah dan menghapus data karyawan. 


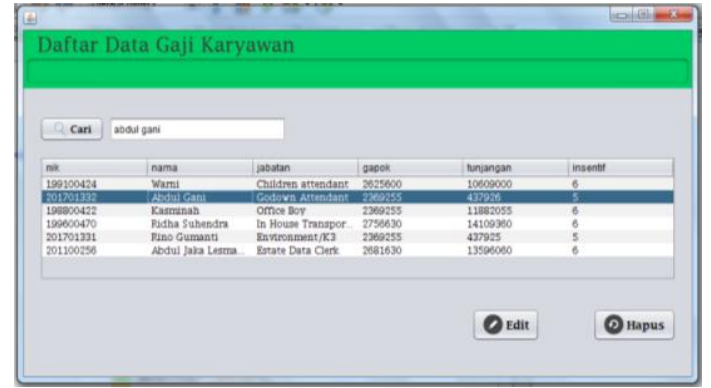

Gambar 10. Rancangan Layar Daftar Data Gaji

e. Form Cetak Laporan Gaji Karyawan Pada gambar rancangan layar 11 digunakan untuk mencetak laporan gaji karyawan guna proses pelaporan gaji karyawan.

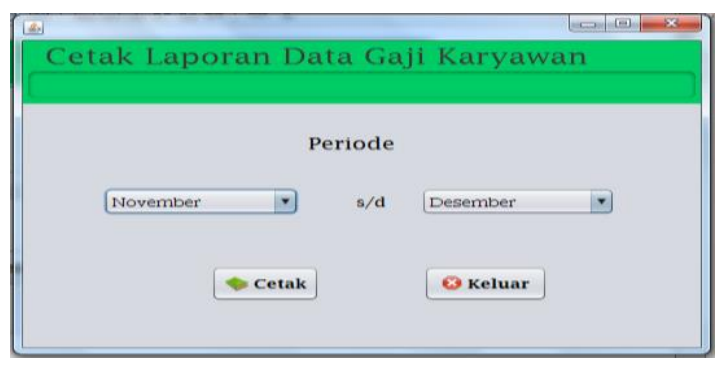

Gambar 11. Rancangan Layar Cetak Laporan Gaji

Berikut ini adalah contoh laporan gaji karyawan pada PT. PP London Sumatra Indonesia Tbk, Gunung Malayu Estate. Berdasarkan rancangan ouput halaman laporan gaji bulanan seperti yang ditunjukkan pada gambar 12, maka dapat dijelaskan pada halaman ini kotak teks untuk inputan periode laporan, jika tombol diklik maka sistem akan menampilkan tabel laporan gaji bulanan sesuai dengan periode yang dipilih.

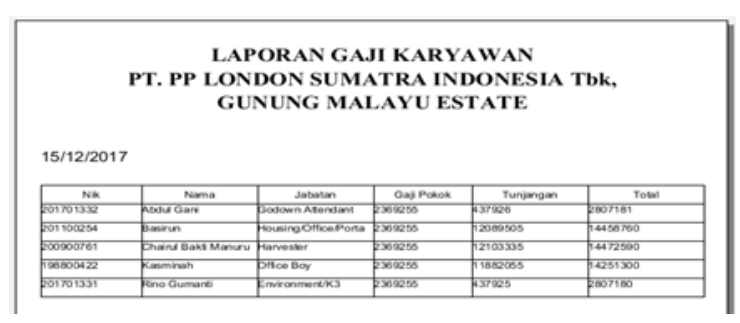

Gambar 12. Contoh Laporan Gaji Karyawan

\section{KESIMPULAN DAN SARAN}

$5.1 \quad$ Kesimpulan

Berdasarkan hasil penulisan dan pembahasan yang dilakukan pada PT. PP London Sumatra Indonesia Tbk, Gunung Malayu Estate maka dapat diambil beberapa kesimpulan, yaitu:

1. Dengan dibuatkannya aplikasi pengolahan data penggajian karyawan ini, maka akan meningkatkan kualitas pelayanan terhadap karyawannya, karena akan menghemat waktu dalam pemprosesan data, serta menghemat waktu dalam laporan penggajian.

2. Dari proses perancangan sistem ini, dapat diketahui bahwa untuk menyusun suatu sistem informasi yang baik, tahap-tahap yang perlu dilakukan adalah dengan mempelajari sistem yang ada atau yang berlaku saat ini, merumuskan masalah yang ada, mencari alternatif penyelesaian untuk masalah yang ada, kemudian merancang suatu sistem yang dapat mengatasi masalah.

\subsection{Saran}

Dari kesimpulan yang telah dikemukakan, maka dihasilkan beberapa saran yang akan dijadikan sebagai bahan masukan yang bermanfaat bagi PT. PP London Sumatra Indonesia Tbk, Gunung Malayu Estate. Adapun saran-saran tersebut sebagai berikut:

1. Agar dalam hal penggelolaan data dari sumber dilakukan penyimpanan pada file database yang baik.

2. Dalam penerapan aplikasi pengembangan sistem informasi penggajian karyawan ini sebaiknya didukung oleh perangkat yang memadai baik dari segi manusia maupun perangkat keras dan lunak. 


\section{DAFTAR PUSTAKA}

[1] Ade Hendini. 2016. Pemodelan Uml Sistem Informasi Monitoring Penjualan Dan Stok Barang (Studi Kasus: Distro Zhezha Pontianak). Jurnal Khatulistiwa Informatika, Vol. IV No. 2

[2] Cosmas Eko Suharyanto, Dkk. 2017. Perancangan Sistem Informasi Penggajian Terintegrasi Berbasis Web (Studi Kasus di Rumah Sakit St. Elisabeth), . Jurnal Teknologi \& Sistem Informasi, Vol. 3 No. 2

[3] Hasan Abdurahman dan Asep Ririh Riswaya. 2014. Aplikasi Pinjaman Pembayaran Secara Kredit Pada Bank Yudha Bhakti. Jurnal Computech \& Bisnis, Vol. 8 No. 2

[4] Jesa Ariawan dan Sri Wahyuni. 2015. Aplikasi Pengajuan Lembur Karyawan Berbasis Web. Jurnal Sisfotek Global, Vol. 5 No. 1

[5] Jogiyanto, Hartono. (1999). Analisis dan Desain Sistem Informasi. Yogyakarta : CV. Andi Offset.

[6] Meza Silvana, Dkk. 2015. Analisis Proses Bisnis Sistem Pembuatan Surat Perintah Perjalanan Dinas Kantor Regional II PT.Pos Indonesia. TEKNOSI, Vol. 01, No. 01

[7] Oktaviani K dan Joni Devitra. 2017. Analisis Dan Perancangan Sistem Informasi Penggajian Karyawan (Studi Kasus : Pt. Kosambi Laksana Mandiri). Jurnal Manajemen Sistem Informasi, Vol. 2 No. 2

[8] Windu Gata, Grace. (2013). Sukses Membangun Aplikasi Penjualan dengan Java. Jakarta : Elex Media Komputindo. 